\title{
Novel device for simultaneous volumetric and $x$-ray diffraction measurements on metal-hydrogen systems
}

\author{
B. A. Talagañis, ${ }^{1,2}$ F. J. Castro, ${ }^{1,2}$ A. Baruj, ${ }^{1,2}$ and G. Meyer ${ }^{1,2}$ \\ ${ }^{1}$ Centro Atómico Bariloche, Instituto Balseiro, Av. Bustillo 9500, 8400 S.C. de Bariloche, Argentina \\ ${ }^{2}$ Consejo Nacional de Investigaciones Científicas y Técnicas (CONICET), Argentina
}

(Received 3 March 2009; accepted 1 June 2009; published online 1 July 2009)

\begin{abstract}
Hydrogen storage materials can form more than one hydride phase. These different phases, in turn, display different hydrogen absorption/desorption capacities, kinetics, and stabilities. Studies aimed at characterizing and improving these materials usually need to correlate hydrogen intake with the precise determination of the hydride phase involved in the process. Here, we present a device designed to perform measurements of well known volumetric techniques with simultaneous $\mathrm{x}$-ray diffraction on the material under study. The compact design can stand up to $6000 \mathrm{kPa}$ of internal pressure while the sample can be heated up to $450{ }^{\circ} \mathrm{C}$. The design process was assisted by finite element modeling and by the use of mock-up prototypes in order to optimize the thermal and under load behaviors. We provide two examples of use for this new device: (1) hydride decomposition in $\mathrm{LaNi}_{5}$ at $115{ }^{\circ} \mathrm{C}$ and (2) formation of $\mathrm{MgCo}$ during the programmed thermal desorption of the $\mathrm{Mg}_{2} \mathrm{CoH}_{5}$ hydride. (C) 2009 American Institute of Physics. [DOI: 10.1063/1.3157086]
\end{abstract}

\section{INTRODUCTION}

In recent years, extensive research has been performed on hydride forming materials due to their widespread applications concerning hydrogen technology such as storage, thermal compression, and purification, among others. ${ }^{1}$ In order to develop appropriate materials for their use in technological applications, several physical properties such as hydrogen absorption/desorption capacity, reaction kinetics, impurity resistance, and degradation by cycling have to be improved. It is also important to obtain a reduction in the costs of raw materials and in the production processes. Volumetric techniques provide essential information about the physical properties of these materials: equilibrium and kinetic properties of the interaction with hydrogen, activation, decrepitation, and cycling degradation, among others.

In a previous work, ${ }^{2}$ we have presented a fully automatized volumetric equipment which allows performing pressure-composition-temperature measurements, isothermal and isobaric reaction kinetics, programmed pressure, and temperature ramps. In spite of the numerous measurements that can be performed with this device, a better understanding of the processes involved in the reactions can be achieved by combining these measurements with in situ $\mathrm{x}$-ray diffraction (XRD) information. In order to attain this objective it is necessary to use a volumetric reactor chamber that can be mounted in the sample holder space of an x-ray diffractometer. Due to the nature of the application of most hydrogen absorbing materials, this reactor should withstand temperatures in the range from room temperature to $450{ }^{\circ} \mathrm{C}$ and pressures between 0 and $6000 \mathrm{kPa}$. Various devices for in situ XRD are either presented in the literature ${ }^{3-6}$ or offered by scientific instrument companies. However, none of them meets all the requirements stated above. For example, Ao et al. ${ }^{3}$ Notten et al. ${ }^{4}$ and Gavra et al. ${ }^{5}$ presented fine designs which are only intended to work at room temperature. The chamber designed by Gross et al. ${ }^{6}$ works at temperatures up to $400{ }^{\circ} \mathrm{C}$ while the upper pressure limit is not mentioned in the publication.

Commercial designs offered by Rigaku Corp. and MRI $\mathrm{GmbH}$ work at high temperature but only under vacuum conditions. Anton Paar GmbH offers a robust chamber that resists up to $1000 \mathrm{kPa}$ of internal pressure at the expense of a large size and weight $(6 \mathrm{~kg})$. Recently, the use of similar devices adapted to synchrotron beamlines has been reported. ${ }^{7}$ Although these instruments offer precise and fast measurements, the access to synchrotron facilities is limited due to beam time selection processes and associated costs.

The aim of this work is to present a simple, compact, and low cost reactor chamber design able to withstand the required hydrogen pressure and sample temperature conditions while also being suitable for simultaneous XRD experiments on the hydrogen-absorbing sample. In principle, the chamber presented here is adapted to work in the small sample holder space of a Philips PW 1700 x-ray diffractometer. Finite element modeling (FEM) techniques were applied during different stages of the design process in order to identify the critical components of the equipment. FEM technique was also used to optimize the thermal behavior of the equipment, in particular, by modeling the water refrigeration circuit of the device. Mechanical tests of components and mock-up prototypes were used to evaluate the behavior of other critical parts of the chamber. The homemade software used to control the volumetric device was modified to simultaneously control the significant parameters of the x-ray diffractometer, namely, goniometer position, step size and measurement time, and recording x-ray counts. The resulting design is versatile enough to be easily adapted to diverse diffractometers.

This paper is organized as follows. Section II presents a general overview of the reactor design and details about the 


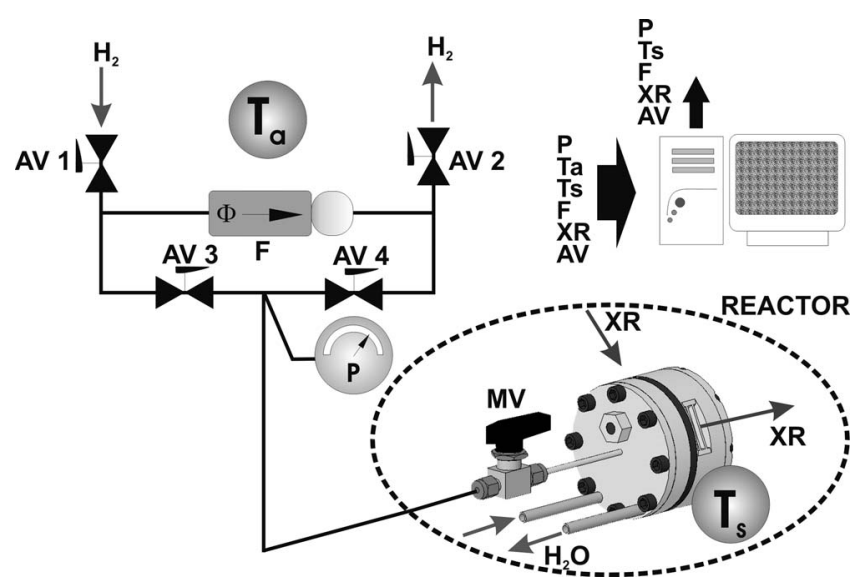

FIG. 1. Schematic drawing of the XRRC and its associated volumetric Sieverts-type device. The volumetric device consists of four automated valves (AV1, AV2, AV3, and AV4), a flow controller $(F)$, and a pressure sensor $(P)$. The reactor can be isolated from the device or media by a MV. A resistance temperature detector (RTD) $\left(T_{S}\right)$ measures the sample temperature. Pressure, room temperature $(T a)$, sample temperature, actual gas flow, $\mathrm{x}$-ray counts, and the position of valves and $\mathrm{x}$-ray goniometer are controlled and recorded via a PC.

selection and setup of critical components. In Sec. III, some examples of application to state of the art hydrogen storage materials are presented.

\section{EQUIPMENT DESIGN}

\section{A. Overview}

The $\mathrm{x}$-ray reactor chamber (XRRC) is adapted to a custom-made volumetric equipment. A schematic view of the equipment is shown in Fig. 1. Automated ball valves, AV1 and AV2, open/close the hydrogen inlet and outlet, respectively. The equipment has two branches. In one of them sits an Omega FMA-7101E flow controller $(F)$ which allows controlling and measuring hydrogen flows up to 20 SCCM (SCCM denotes cubic centimeter per minute at STP). The other branch has two automated ball valves (AV3 and AV4) and the reactor connection between them. A manual valve (MV) is located at the reactor gas entry. This valve remains open during the operation of the equipment but can be closed when the XRRC is removed. By doing this, the sample to be studied can be prevented from getting in contact with air, facilitating the reactor handling inside a glovebox.

The XRRC main body and lids have been constructed in stainless steel. The external diameter of the reactor is $80 \mathrm{~mm}$, which is the sample holder space in the diffractometer. Two $0.5 \mathrm{~mm}$ thickness beryllium windows allow XRD measurements in the $2 \Theta$ range from $10^{\circ}$ to $90^{\circ}$. These beryllium windows are glued to window frames in the stainless steel walls with a two component adhesive (Araldite 2014, Huntsman Advanced Materials $\mathrm{GmbH}$ ). A water refrigeration circuit is carved within the reactor walls and back lid. The front cover contains the water inlet and outlet, referenced with the $\mathrm{H}_{2} \mathrm{O}$ arrows in Fig. 1. The sample holder can accommodate $\sim 2 \mathrm{~g}$ of hydride and its temperature and pressure can be set in the range from room temperature to $450{ }^{\circ} \mathrm{C}$ and from vacuum to $6000 \mathrm{kPa}$, respectively.

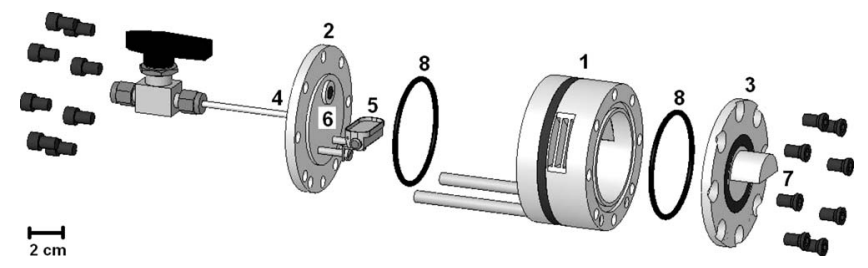

FIG. 2. Exploded view of the XRRC concept. (1) Main body. (2) Front cover. (3) Back lid. (4) Gas inlet/outlet. (5) Sample holder. (6) Electric feedthrough. (7) External nose. (8) Silicone O rings.

The equipment can be operated in several ways. The XRRC can be quickly filled up with hydrogen by opening only AV1 and AV3. Fast reactor evacuation is achieved by simultaneously opening AV2 and AV4, after closing AV1 and AV3. On the other hand, by opening only AV1 and AV4, the amount of hydrogen sent to the reactor is controlled and measured by the flow controller $F$. This operation mode is useful, for example, to measure the hydrogen absorption properties of the samples. Similarly, controlled desorption can be set and measured by opening AV2 and AV3.

The parameters of the experiment are set through a Visual Basic for MS Windows-based software designed in our laboratory. This user-friendly software controls the experiment progress, the goniometer position, and the real time acquisition of the variables involved: $\mathrm{x}$-ray counts $(X R)$, pressure $(P)$, sample temperature $\left(T_{s}\right)$, room temperature $(T a)$, and gas flow $(F)$. The open/close position of each of the four AV automated valves is switched by the program according to the experiment setup in order to perform absorption or desorption measurements.

\section{B. Mechanical design}

The reactor consists of three main parts (Fig. 2): the main body (referenced as part 1 in Fig. 2), the front cover (2), and the back lid (3). The front cover supports the gas inlet/outlet (4) on the external side, the sample holder (5) on the internal side, and an electric feedthrough (6). Further details on the sample holder and the feedthrough will be presented in Sec. II C. The back lid has an external nose (7) that fits into the diffractometer mounting. $\mathrm{O}$ rings (8) are placed between the main body and the front cover and back lid to prevent gas leakage. A photograph of the actual XRRC is shown in Fig. 3.

The tube-shaped main body is $80 \mathrm{~mm}$ in diameter, 40 $\mathrm{mm}$ in height, and the wall thickness is $30 \mathrm{~mm}$. It has been machined from a single solid cylindrical piece of stainless steel. Two window frames were machined in the main body walls. The dimensions of each frame are $20 \mathrm{~mm}$ long and

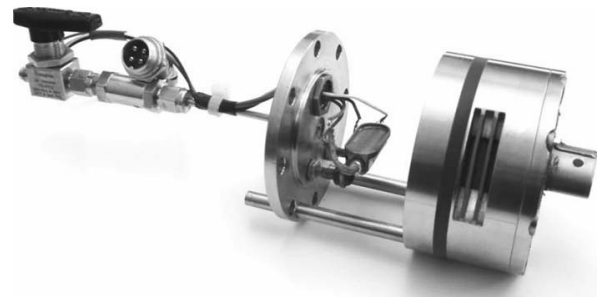

FIG. 3. Photograph of the actual XRRC. 


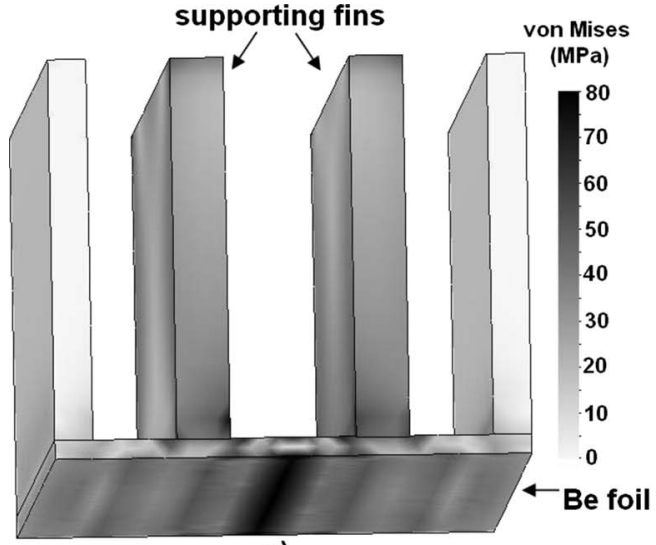

a)

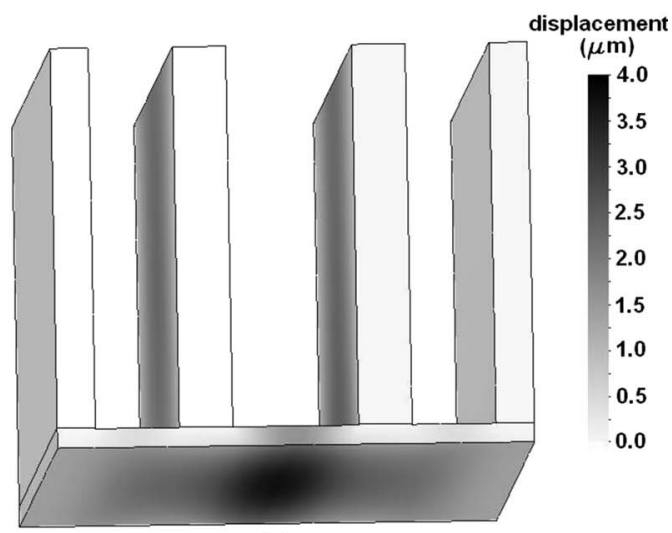

b)

FIG. 4. FEM of the beryllium window behavior under applied pressure (6000 kPa). (a) Resolved von Mises stress. (b) Displacement in the direction normal to the window surface.

$12.5 \mathrm{~mm}$ wide, thus achieving a $2 \Theta$ range from $10^{\circ}$ to $90^{\circ}$ in the diffraction measurements. Each frame contains two longitudinal fins (thickness of $1 \mathrm{~mm}$, Fig. 2) included to reduce the stress on the Be walls under internal pressure. The inner side of the frames and fins has been machined flat. Onto this internal flat surface, beryllium windows were glued. The thickness of the Be windows is limited to $0.5 \mathrm{~mm}$ in order to allow the x-rays to pass through them.

Provided that these beryllium foils have to resist up to $6000 \mathrm{kPa}$ of internal pressure, especial attention was paid to their design and placement. A FEM simulation of the windows final design under applied pressure is shown in Fig. 4. The beryllium foil is pressed against the supporting fins reducing the strain on the window. As can be seen in Fig. 4(a), a maximum stress on the Be foil is below its yield stress (200 $\mathrm{MPa}$ ). Deformation, Fig. 4(b), is about a few microns. By using a Si standard it was estimated that both windows, with Be foils and fins included, reduce by $\sim 80 \%$ the counts collected by the X-ray detector.

As mentioned in Sec. II A, the beryllium windows are glued to the cylinder with an adhesive. The adhesive shear and tensile strength were tested at various temperatures and with various surface preparations in order to assure that it is capable to withstand the working conditions. Maximum resistance values obtained agreed with those stated by the manufacturer. The union was also tested to determine gas leakage at $6000 \mathrm{kPa}$ and up to $60{ }^{\circ} \mathrm{C}$. A mock-up reactor was sealed with the adhesive and filled with hydrogen up to 6000 $\mathrm{kPa}$. The reactor pressure was monitored during $24 \mathrm{~h}$. No pressure drop was detected within the $1 \mathrm{kPa}$ accuracy of the pressure detector.

\section{Sample holder and experiment control}

The sample holder (labeled as 5 in Fig. 2) is made of copper in order to maximize the heat transfer from the electrical heater and to obtain a uniform temperature profile on the sample. It encloses an electrical heater (OMEGA CIR101121/240V) and a temperature sensor (OMEGA Pt100KN2515CLA). Figure 5 shows a detailed view of the sample holder arrangement. Because most hydride forming materials are powders after hydrogen absorption, the upper part of the sample holder acts as a container. The powder has to fill the sample bed in such a way that its upper surface matches the diffraction plane of the diffractometer. The container volume has been designed to hold $\sim 2 \mathrm{~g}$ of $\mathrm{LaNi}_{5}$ sample. Although the actual amount of powder would depend on its chemical composition, the holder simple design and low fabrication costs make easy to have some holders with different container size suitable for other hydrides.

Electric power for the heater and the temperature signal are transmitted through the front cover of the reactor via an electrical feedthrough PAVE-Seal 2064 (labeled as 6 in Fig. 2). The feedthrough stands up to $6000 \mathrm{kPa}$ of pressure and temperatures up to $80^{\circ} \mathrm{C}$. The temperature of the sample is controlled via a PID DELTA DTB 4824-VR controller. The control software mentioned in Sec. II A receives the temperature signal acquired by the controller and transmits the temperature to the personal computer (PC) via a USB-RS485 port using a communications protocol MODBUS RTU.

The parameters of the XRD measurement set by the user and the control of the goniometer are handled by the same software via a RS-232 port that connects the PC to the diffractometer. The other parameters of the experiment such as reactor pressure, room temperature, gas flow, and actuated valve position are also handled by the software via an acquisition card OMEGA USB OMB-DAQ-3001.

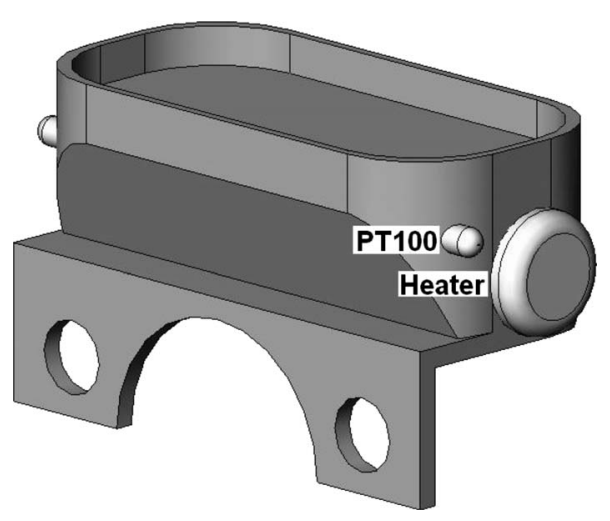

FIG. 5. Schematic drawing of the sample holder. 


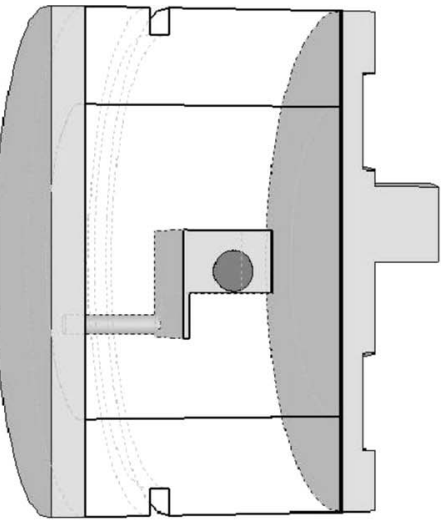

a)

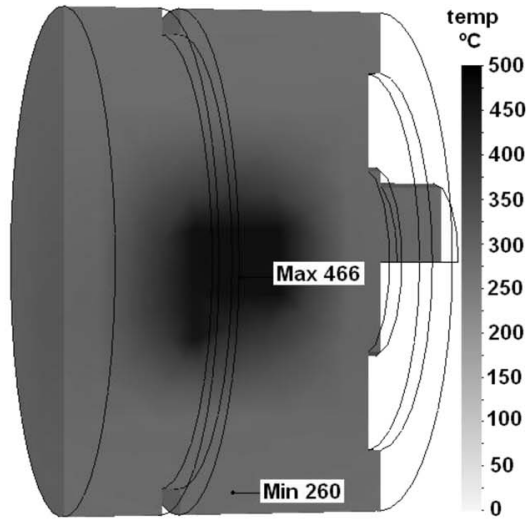

b)

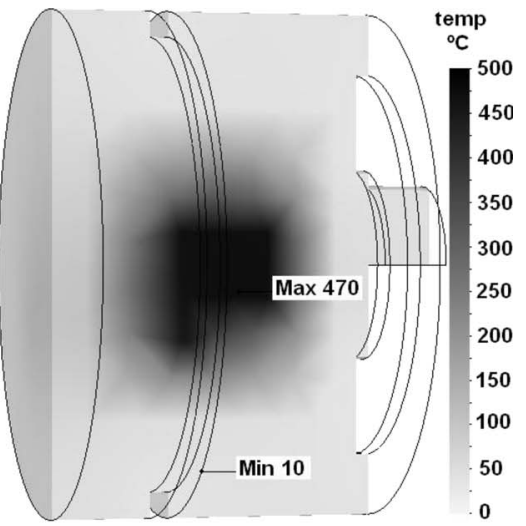

c)

FIG. 6. FEM thermal analysis of the reactor containing hydrogen at $6000 \mathrm{kPa}$. (a) Cut view of the reactor chamber. (b) Equilibrium distribution of temperatures without water refrigeration when the sample holder is at $450^{\circ} \mathrm{C}$. (c) Distribution of temperatures with water refrigeration.

\section{Thermal design}

In any working condition, the temperature on the reactor body and on its lids must not exceed $60{ }^{\circ} \mathrm{C}$. Otherwise, the adhesive that fixes the Be windows, the electric feedthrough, and/or the diffractometer would be damaged. In this sense, the extreme condition would be that of having a sample at a temperature of $450{ }^{\circ} \mathrm{C}$ under $6000 \mathrm{kPa}$ of hydrogen. It was experimentally found that without refrigeration the temperature on the reactor body largely exceeds the $60{ }^{\circ} \mathrm{C}$ limit under those conditions. The behavior of the reactor under these requirements was also simulated using FEM techniques. Figure 6(a) shows the model used to perform the calculations. In this model, the internal part of the reactor was filled with a material that has the thermal conductivity of hydrogen gas at high pressure. The model was built using 8050 tetrahedral elements with 12362 nodes (model without refrigeration circuit) or 10965 elements and 16231 nodes (model including refrigeration). FEM calculations reflected experimental observations under stationary conditions. Without refrigeration, the temperature on the body walls exceeded $260{ }^{\circ} \mathrm{C}$ [Fig. 6(b)]. Aided by FEM calculations, a water refrigeration circuit was designed and, after matching the design with the requirements, drilled in the reactor body. The water inlet and outlet are attached to the reactor body (Fig. 2) and pass through holes drilled in the front cover. The water flow enters through the front cover, flows by the channel drilled in the body, goes to the rear lid, and finally returns to the front outlet (Figs. 1-3 and 6). Figure 6(c) shows the temperature profile calculated with FEM. The temperature on the sensible parts of the reactor never exceeds $50{ }^{\circ} \mathrm{C}$. This result was confirmed on the chamber prototype.

\section{OPERATION EXAMPLES}

\section{A. Analysis of the $\mathrm{LaNi}_{5}-\mathrm{H}_{2}$ system}

The $\mathrm{LaNi}_{5}$ system is the flagship of hydride forming materials. It has received considerable attention over the last years, being its main characteristics well researched. ${ }^{8}$ At temperatures higher than $80{ }^{\circ} \mathrm{C}$, the hydriding process presents two plateaus on the isotherms, which are detected in standard volumetric measurements. These two plateaus cor- respond to the formation of the hydride phases $\mathrm{LaNi}_{5} \mathrm{H}_{3}$ ( $\beta$ phase) and $\mathrm{LaNi}_{5} \mathrm{H}_{6}(\gamma$ phase $){ }^{9}$ The XRRC allows combining the volumetric measurements with in situ XRD and therefore correlating hydride formation with the concentration of hydrogen in the sample.

In order to perform the experiment, $2 \mathrm{~g}$ of fully activated $\mathrm{LaNi}_{5}$ sample ( $\alpha$ phase) was loaded in the XRRC inside a glovebox. The chamber was then connected to the volumetric equipment and mounted in the diffractometer. The $\mathrm{LaNi}_{5}$ sample was charged with $\mathrm{H}_{2}$ at room temperature until all the powder was in the hydrided $\gamma$ phase. Then, while keeping the pressure at $4000 \mathrm{kPa}$, it was heated up to $115^{\circ} \mathrm{C}$, which was the temperature selected for this experiment. The initial pressure was $4000 \mathrm{kPa}$ and the equipment was set for isothermal desorption measurement: AV1 and AV4 in closed position and AV2, AV3, and MV in opened position (Fig. 1). The amount of hydrogen evacuated from the XRRC was measured and controlled via the flow controller ( $F$ in Fig. 1). The angular inspection range was set to $2 \Theta=27^{\circ}-32^{\circ}$. This range includes peaks of the three phases involved $(\alpha, \beta$, and $\gamma){ }^{9}$ Figure 7 shows the desorption isotherm on the left side. The right side presents the XRD obtained at various stages. The diffraction profile at the beginning of the experiment $(4000 \mathrm{kPa})$ only has the $\gamma$ phase peak indicating that the sample is fully hydrided. From 3000 to $2600 \mathrm{kPa}$, as the sample releases hydrogen, the diffraction profiles show the coexistence of $\gamma$ and $\beta$ phases. After this stage, the $\gamma$ phase completely decomposed into $\beta$. From 2400 to $2200 \mathrm{kPa}$ the profiles show the coexistence of $\beta$ and $\alpha$. When the pressure is below $2000 \mathrm{kPa}$ the sample is fully dehydrided and the profiles only show the peak related to the presence of $\alpha$ phase. The experiment showed the expected match between volumetric and XRD measurements, thus confirming the usefulness of this device.

\section{B. Thermal desorption spectroscopy combined with XRD}

Thermal desorption spectroscopy (TDS) is a nonisothermic technique oriented to the study of desorption kinetics. Briefly, the experiment starts with a sample charged with hydrogen and cooled down to a temperature where hydrogen 


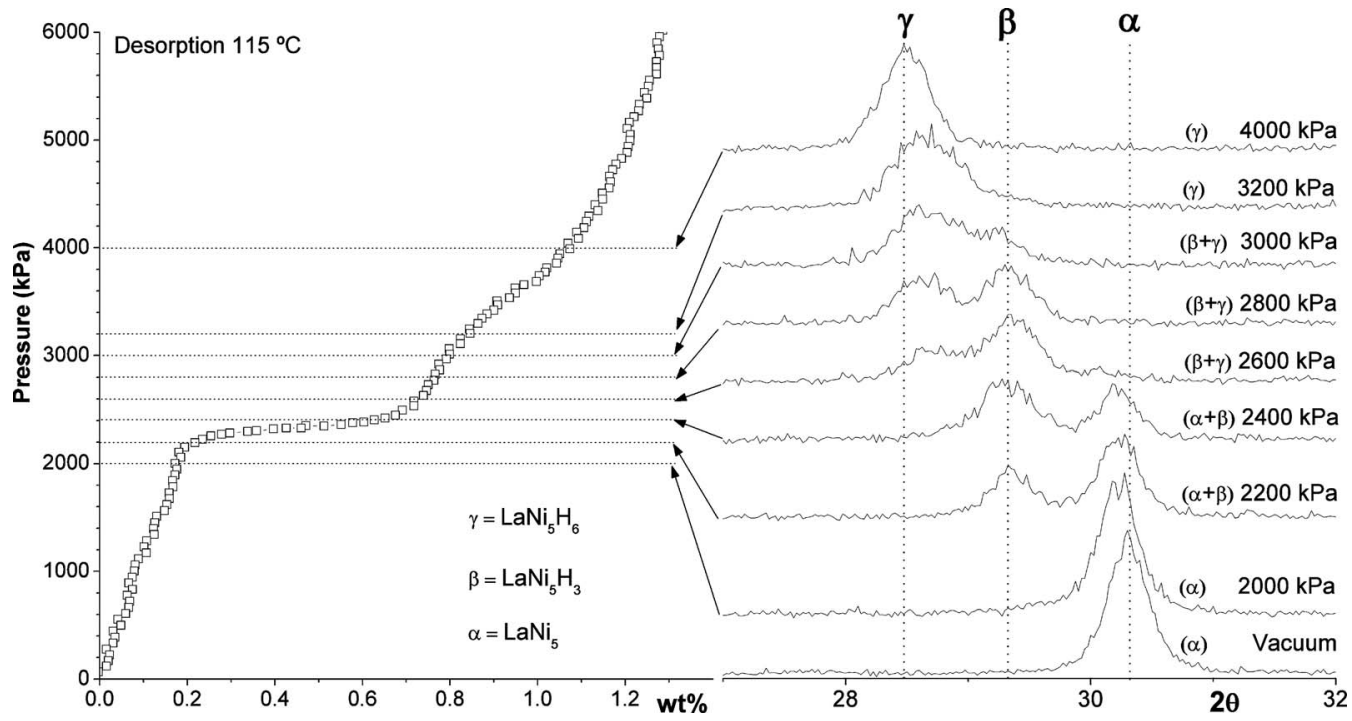

FIG. 7. Left: desorption isotherm of the $\mathrm{LaNi}_{5}-\mathrm{H}_{2}$ system at $115^{\circ} \mathrm{C}$. Right: evolution of the system diffraction profile in the $2 \Theta$ range from $27^{\circ}$ to $32^{\circ}$ during the desorption isotherm.

mobility is negligible. Then, it is heated following a predetermined temperature profile while the amount of gas released from the material is measured. The result, usually called a TDS spectrum, is a plot of the flow of desorbed gas as a function of temperature. As the temperature varies linearly with time, the flow of gas can also be plotted as a function of time. The dependence of the highest desorption flow with the rate of temperature change and the shape of the flow versus temperature plots help to calculate the activation energy and to identify the dominant desorption process, respectively.

The complex hydride $\mathrm{Mg}_{2} \mathrm{CoH}_{5}$ was selected to illustrate this kind of measurement. This hydride is attractive for hydrogen storage applications due to its high gravimetric capacity (4.5 wt \%) and its high hydrogen volumetric density (about $100 \mathrm{~kg} \mathrm{H} / \mathrm{m}^{3}$ ). ${ }^{10}$ The study of this hydride decomposition is especially interesting because $\mathrm{Mg}_{2} \mathrm{Co}$ is not a

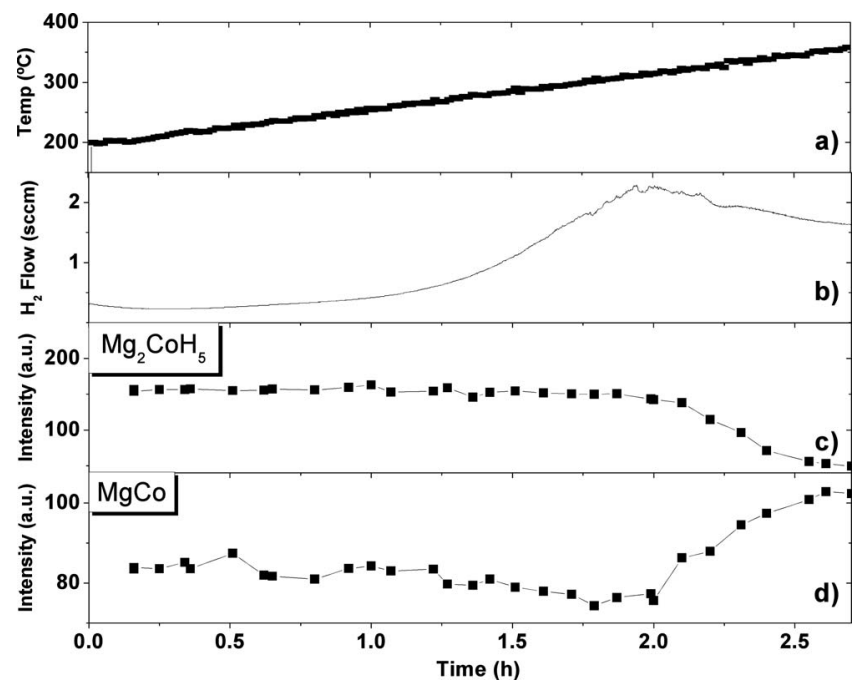

FIG. 8. Time evolution during the TDS measurement of $\mathrm{Mg}_{2} \mathrm{CoH}_{5}$ decomposition. (a) Temperature ramp $\left(1{ }^{\circ} \mathrm{C} / \mathrm{min}\right)$. (b) TDS spectrum. (c) Evolution of the $\mathrm{Mg}_{2} \mathrm{CoH}_{5}$ peak height $\left(2 \Theta=24.03^{\circ}\right)$. (d) Evolution of the $\mathrm{MgCo}$ peak height $\left(2 \Theta=13.39^{\circ}\right)$. stable phase in the $\mathrm{Mg}-\mathrm{Co}$ system. Hydrogen desorption in this system takes place at temperatures of $300{ }^{\circ} \mathrm{C}$ or higher. After desorption, usual XRD measurements at room temperature detect the presence of multiple decomposition phases such as $\mathrm{MgCo}, \mathrm{Mg}$, and $\mathrm{Co}$,

$$
2 \mathrm{Mg}_{2} \mathrm{CoH}_{5} \rightleftarrows \mathrm{MgCo}+3 \mathrm{Mg}+\mathrm{Co}+5 \mathrm{H}_{2} \text {. }
$$

In particular, it is not clear whether the $\mathrm{MgCo}$ phase forms during the hydride decomposition at high temperature or later when the sample is cooled down to room temperature. Performing XRD simultaneously with TDS allows establishing which phases are formed during hydride decomposition and the moment when the phase transformation occurs.

For this experiment, $1 \mathrm{~g}$ of $\mathrm{Mg}_{2} \mathrm{CoH}_{5}$ was loaded in the sample holder of the XRRC inside a glovebox. The reactor was then mounted in the diffractometer and connected to the volumetric equipment and to the water refrigeration circuit (Fig. 1).

Placing AV1 in closed position and the other valves in open position, the system was evacuated at room temperature. Due to its slow reaction kinetics at this temperature, the hydride did not decompose during this procedure. AV4 was then turned to closed position and the temperature ramp started. This valve configuration forces the hydrogen desorbed from the sample to cross through the flow controller $(F)$, which is used as a flow meter during this experiment. The desired temperature ramp $\left(1^{\circ} \mathrm{C} / \mathrm{min}\right)$ and angular inspection intervals $\left(2 \Theta=11.9^{\circ}-14.9^{\circ}\right.$ and $2 \Theta=22.5^{\circ}$ $-25.5^{\circ}$ ) are set by the user in the control software. The selection of the angular inspection intervals is based on the known diffraction patterns of the phases whose evolution is followed, i.e., $\mathrm{Mg}_{2} \mathrm{CoH}_{5}$ and $\mathrm{MgCo}{ }^{11,12}$ There are no diffraction peaks of $\mathrm{Mg}$ and $\mathrm{Co}$ within the selected angular intervals. ${ }^{13,14}$ The presence of $\mathrm{Mg}_{2} \mathrm{CoH}_{5}$ was estimated from the peak located at $2 \Theta=24.03^{\circ}$ which corresponds to the crystallographic plane (101) of the tetragonal structure. Similarly, the presence of the MgCo phase was estimated from 
the peak located at $2 \Theta=13.39^{\circ}$ which corresponds to the crystallographic plane (111) of the cubic system.

Figure 8 shows the evolution in time of the variables during the experiment. Figure 8(a) is the applied temperature profile. Figure 8(b) shows the flow of $\mathrm{H}_{2}$ through the flow meter (TDS spectrum). Figures 8(c) and 8(d) show the evolution of the area of the selected $\mathrm{Mg}_{2} \mathrm{CoH}_{5}$ and $\mathrm{MgCo}$ peaks, respectively. The decomposition of the hydride phase $\mathrm{Mg}_{2} \mathrm{CoH}_{5}$ starts at about $300{ }^{\circ} \mathrm{C}$ [Fig. 8(c)], coinciding with the onset of $\mathrm{MgCo}$ formation [Fig. 8(d)]. It can be therefore concluded that the formation of $\mathrm{MgCo}$ is a direct consequence of hydride decomposition and not of temperature drop after desorption. This example demonstrates how this novel reactor can be readily applied to perform the combined in situ XRD with a sophisticated dynamic technique like TDS.

\section{ACKNOWLEDGMENTS}

The authors gratefully acknowledge the help of $\mathrm{P}$. Bavdaz, R. Stuke, and C. Talauer with the mechanical design and construction of the reactor. R. Saliba helped with the FEM simulations. This work is supported by CNEA (Grant
No. P5-PID-95-2), ANPCyT (Grant Nos. PICT-12-15065 and PICT-12-12453), and CONICET (Grant Nos. PIP-02751/ 2000 and PIP 6448/2005).

${ }^{1}$ G. Sandrock, J. Alloys Compd. 293, 877 (1999).

${ }^{2}$ G. Meyer, D. Rodriguez, F. Castro, and G. Fernández, Proceedings of the 11th World Hydrogen Energy Conference, Stuttgart, 1996 (unpublished), Vol. 2, pp. 1293-1298.

${ }^{3}$ B. Ao, X. Wang, Y. Wei, and Y. Zhang, J. Appl. Crystallogr. 40, 796 (2007).

${ }^{4}$ P. Notten, J. Daams, A. De Veirman, and A. Staals, J. Alloys Compd. 209, 85 (1994).

${ }^{5}$ Z. Gavra and J. Murray, Rev. Sci. Instrum. 57, 1590 (1986).

${ }^{6}$ K. Gross, S. Guthrie, S. Takara, and G. Thomas, J. Alloys Compd. 297, 270 (2000).

${ }^{7}$ P. J. Chupas, M. F. Ciraolo, J. C. Hanson, and C. P. Grey, J. Am. Chem. Soc. 123, 1694 (2001).

${ }^{8}$ B. Sakintuna, F. Lamari-Darkrim, and M. Hirscher, Int. J. Hydrogen Energy 32, 1121 (2007).

${ }^{9}$ E. Akiba, K. Nomura, and S. Ono, J. Less-Common Met. 129, 159 (1987).

${ }^{10}$ I. González Fernández, G. O. Meyer, and F. C. Gennari, J. Alloys Compd. 464, 111 (2008)

${ }^{11}$ JCPDS Card No. 44-1160.

${ }^{12}$ JCPDS Card No. 44-1149.

${ }^{13}$ JCPDS Card No. 04-0770.

${ }^{14}$ JCPDS Card No. 05-0727. 